\title{
Fracture Resistance of Resilon-Filled Roots Following Different Retreatment Techniques
}

\author{
Fatma Asheibi ${ }^{1,2}$, Alison J.E. Qualtrough ${ }^{1}$ and Anthony Mellor ${ }^{1}$ \\ ${ }^{1}$ School of Dentistry, University of Manchester, Manchester, UK \\ ${ }^{2}$ Garyounis University, Faculty of Dentistry, Benghazi, Libya
}

Correspondence should be addressed to: FatmaAsheibi; Fafadent1@yahoo.com

Received Date:19February 2014; Accepted Date:31March 2014; Published Date: 31 May 2014

Academic Editor: Ronald Ordinola Zapata

Copyright (C) 2014 Fatma Asheibi, Alison J.E.Qualtrough and Anthony Mellor. Distributed under Creative Commons CC-BY 3.0

\begin{abstract}
The aim of this study was to investigate whether endodontically retreated teeth filled with Resilon are more resistant to fracture than those filled with guttapercha following hand or rotary removal techniques.

Seventy-two upper anterior human teeth were selected, decoronated and reduced to $12 \mathrm{~mm}$. The canals were shaped using rotary ProTaper files and randomly assigned into two groups $(\mathrm{n}=36)$. Obturation was performed using guttapercha/AH-Plus in Group 1 and Resilon/RealSeal in Group 2. The roots were stored for one week at $37^{\circ} \mathrm{C}$. The roots were then randomly allocated into three subgroups: A ( $n=10)$, no further treatment was performed. In $B(n=13)$, the filling was removed using hand $\mathrm{K}$-files and in $\mathrm{C}(\mathrm{n}=13)$ using ProTaper retreatment files. Subgroups $B$ and $C$ were refilled using the same materials as used in the primary treatment and stored for one week. Three roots from each of the four subgroups were left unfilled to act as a control $(n=12)$. All the roots were embedded in resin and subjected to fracture in a universal testing machine. Data were analysed using Kruskal-Wallis with multiple pairwise comparisons.

Resilon-refilled roots showed no significance difference in fracture resistance compared with guttapercha-refilled roots regardless of the retreatment technique. There was no significant difference in fracture resistance between the two retreatment techniques.
\end{abstract}

When used as a root filling material, Resilon was found not to increase the fracture resistance of primarily and previously root filled teeth regardless of the retreatment technique.

Keywords: Guttapercha; ProTaper; Resilon; retreatment; root fracture.

\section{Introduction}

Root fracture is one of the causes of endodontic treatment failure and usually results in tooth extraction (Tamse 2006).
Endodontic treatment inherently requires the removal of tooth structure in order that a straight line access is created and to permit thorough cleaning and shaping (Goodacre 2004). The strength of the 
treated tooth is directly proportional to the quantity and quality of the remaining tooth structure. The more tooth structure is removed, the likelihood of tooth fracture increases (Sornkul and Stannard 1992).

Theoretically, if the root canal filling material bonds to the root dentine, in addition to providing a good seal, fracture resistance of the root may be improved (Teixeira et al. 2004a). Guttapercha has favourable properties, such as dimensional stability, biocompatibility and removability which make it the most commonly used obturation material (Miner et al. 2006). However, its main limitation is that it does not bond to the root dentine or to any sealer (Teixeira et al. 2004a). Therefore, it does not provide any resistance to fracture of the root canal treated teeth (Williams et al. 2006; Hammad et al. 2007).

A thermoplastic synthetic polymer-based root filling material, Resilon, was introduced in 2004 (Teixeira and Trope 2004). It is comprised of a matrix (copolymer of polycaprolactone and urethane dimethacrylate), bioactive glass and radiopaque fillers (bismuth oxychloride and barium sulphate) (Teixeira et al. 2004a). It is produced in points as is guttapercha, and can be used to obturate the canal using either cold lateral condensation or warm filling techniques. If indicated, it can be removed using heat or solvents as with guttapercha (Hammad et al. 2008). The literature indicates that Resilon has some promising properties compared with guttapercha in that it bonds to the dentine (Teixeira et al. 2004a), provides more favourable resistance to leakage (Shipper et al. 2004) and improves resistance to fracture (Teixeira et al. 2004b).

The effect of Resilon in increasing the fracture resistance of root canal treated teeth has been investigated in primary root canal treatment (Hammad et al. 2007; Monteiro et al. 2011), but its significance in retreatment cases has not been addressed nor have the effects of different techniques for its removal as a filling material. In cases of retreatment, roots may become even more susceptible to fracture as a result of further removal of dentine. Furthermore, any remaining material may interfere with the bonding of Resilon to the dentine wall (Schwartz 2006).

Therefore, the aim of this study was to investigate the fracture resistance of previously root treated roots refilled with Resilon in comparison with guttapercha following retreatment using either hand Kfiles or ProTaper retreatment files. The null hypothesis is that there would be no significant difference in fracture resistance between roots refilled with Resilon compared with guttapercha using the two different retreatment techniques.

\section{Materials and Methods}

The use of extracted human teeth in this study was approved by the Ethics Committee at the University of Manchester. Eighty-five upper anterior teeth were disinfected in 5\% sodium hypochlorite $(\mathrm{NaOCl})$ (Procter and Gamble, Weybridge Surrey, UK) for 10 minutes and stored in normal saline. Teeth were carefully examined under illumination and magnification $(\mathrm{x} 40)$ to exclude any roots with cracks or fractures, resorption, immature apices and caries or roots with curvature more than $5^{\circ}$, as described by Schneider (1971). The experimental design and the method of samples preparation for the mechanical test used in the present experiment have been used in previous studies (Wilcox et al. 1997; Lertchirakarn et al. 2002; Hammad et al. 2007).

\section{Teeth Preparation and Obturation}

The crowns were removed and the length of the roots was reduced to $12 \mathrm{~mm}$ using a diamond wheel saw with water cooling (Model 650, South Bay Technology inc., California, USA). Teeth were identified (central incisors, lateral incisors and canines) to aid in their allocation into groups for obturation. Bucco-lingual (BL) and Mesio-Distal (MD) dimensions of the roots were measured and roots with comparable dimensions were selected (Table 1). From the initial sample, 72 roots (28 central incisors, 22 lateral incisors and 22 canines) were suitable for the study. A 
size 10 K-file (VDW GmbH, Munich, Germany) was used to determine the working length, which was set at $1 \mathrm{~mm}$ short of the apical foramen. Root canals were prepared using rotary ProTaper files (DentsplyMaillefer, Ballaigues, Switzerland) to a final size of F3 instrument. $1 \% \mathrm{NaOCl}$ was used as an irrigant. When the preparation was finished, the canals were irrigated with $17 \%$ of ethylene-diamine-tetra-acetic acid (EDTA) (PPH Cerkamed, Sandomierska, Poland) and distilled water. The roots were randomly allocated into two groups using stratified sampling $(n=36: 14$ central incisors, 11 lateral incisors and 11 canines) according to the filling material: Group 1 was filled with ProTaperguttapercha (GP) (DentsplyMaillefer,

Ballaigues, Switzerland) and AH-Plus sealer (DentsplyDeTrey GmbH, Konstanz, Germany) and Group 2 was filled with Resilon/ReaSeal sealer (Pentron Corp., Wallingford, US).

The root canals were dried using paper points (Diadent, Chungcheongbuk-do,
Korea). In Group 1, a ProTaper GP master cone was selected (fitted the canal to the working length with tug-back) coated with the sealer and inserted into the canal. The cone was compacted using a System B plugger of fine-medium size (SybronEndo, Glendora, USA) with the temperature set at $200^{\circ} \mathrm{C}$. Light vertical pressure was applied for 10 seconds and then, the plugger was withdrawn by applying a one-second heat burst. The canal was backfilled using Obtura III (Obtura Spartan, Earth City, Missouri, USA) at $200^{\circ} \mathrm{C}$.

Group 2 was filled with Resilon/ReaSeal sealer using the thermal technique as described for Group 1. The primer was applied into the canal after drying and the excess was removed using a paper point. The sealer was carried on a Resilon master cone (30/0.06). As per the manufacturers' instructions, the temperature was adjusted to $150^{\circ} \mathrm{C}$ for System B and Obtura III. After completion of obturation, the coronal part was light cured for 40 seconds. All roots were stored for one week at $37^{\circ} \mathrm{C}$ and $100 \%$ humidity in air-tight containers.

Table 1: Means and Standard Deviations (SD) Of Bucco-Lingual and Mesio-Distal Dimensions (Mm) Of the Roots of All Subgroups

\begin{tabular}{|c|c|c|c|c|c|c|c|}
\hline \multirow{2}{*}{ Group } & \multirow{2}{*}{ Control } & \multicolumn{3}{|c|}{ Guttapercha } & \multicolumn{3}{|c|}{ Resilon } \\
\hline & & ${ }^{*} \mathrm{~A}$ & ${ }^{* *} \mathrm{~B}$ & ${ }^{* * *} \mathrm{C}$ & A & B & $\mathrm{C}$ \\
\hline $\begin{array}{l}\text { Mean } \\
\text { dimension (SD) }\end{array}$ & $\begin{array}{l}6.81 \\
(0.36)\end{array}$ & $\begin{array}{l}6.67 \\
(0.33)\end{array}$ & $\begin{array}{l}6.91 \\
(0.48)\end{array}$ & $\begin{array}{l}6.96 \\
(0.58)\end{array}$ & $\begin{array}{l}6.97 \\
(0.46)\end{array}$ & $\begin{array}{l}6.71 \\
(0.39)\end{array}$ & $\begin{array}{l}6.85 \\
(0.38)\end{array}$ \\
\hline $\begin{array}{l}\text { Mean } \\
\text { dimension (SD) }\end{array}$ & $\begin{array}{l}4.86 \\
(0.39)\end{array}$ & $\begin{array}{l}4.59 \\
(0.41)\end{array}$ & $\begin{array}{l}4.69 \\
(0.43)\end{array}$ & $\begin{array}{l}4.75 \\
(0.48)\end{array}$ & $\begin{array}{l}4.62 \\
(0.39)\end{array}$ & $\begin{array}{l}4.84 \\
(0.42)\end{array}$ & $\begin{array}{l}4.68 \\
(0.34)\end{array}$ \\
\hline
\end{tabular}

*A: No retreatment

**B: Retreated with hand K-files and refilled with the same material in the first treatment

${ }^{* * *} \mathrm{C}$ : Retreated with ProTaper retreatment files and refilled with the same material in the first treatment

\section{Retreatment}

The roots in each group were randomly assigned into three subgroups (Figure 1):

A $(n=10: 4$ central incisors, 3 lateral incisors, 3 canines): no further treatment was performed.

B (n=13: 5 central incisors, 4 lateral incisors, 4 canines): the root filling material was removed using hand $\mathrm{K}$-files.
C $(n=13: 5$ central incisors, 4 lateral incisors, 4 canines): the root filling material was removed using ProTaper retreatment files (Quality Endodontic Distributors Ltd, Peterborough, UK).

In subgroup $\mathrm{B}$, the coronal $2 \mathrm{~mm}$ of the filling was removed using Gates-Glidden drills (Quality Endodontic Distributors Ltd, Peterborough, UK), then two drops of eucalyptus oil (PPH Cerkamed, Sandomierska, Poland) were placed in the 
canal. Hand K-files were then used in a circumferential quarter-turn push-pull filing motion until the filling material was removed, such that no material was seen on the file or on the canal walls by naked eye. During removal, one or two drops of eucalyptus oil were applied as required. The final K-file size used was 30. third of the filling. The speed of the motor was set at $500 \mathrm{rpm}$ according to the manufacturers' recommendations. Eucalyptus oil was applied as in the subgroup B. D2 and D3 were then used to remove the filling from the middle and the apical thirds respectively.

In subgroup C, ProTaper retreatment D1 file was used to remove the coronal one-

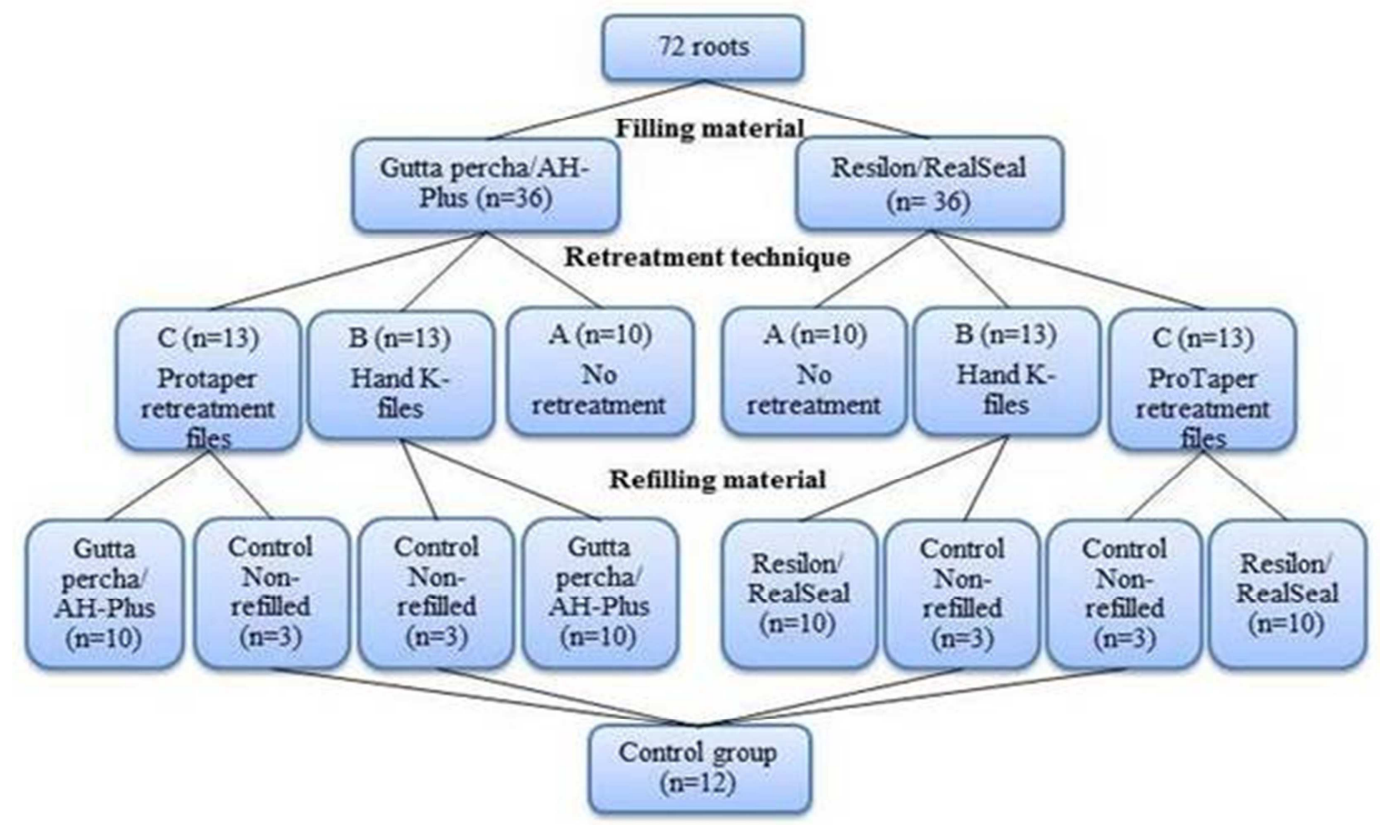

Figure 1: Groups and Subgroups Allocation according to Filling Materials and Retreatment Techniques

After completion of removal, the canals were irrigated with $3 \mathrm{~mL} \mathrm{1 \%} \mathrm{NaOCl,} 5 \mathrm{~mL}$ $17 \%$ EDTA and finally with $10 \mathrm{~mL}$ distilled water. The root canals were re-filled using the same materials and technique used in the first treatment of each subgroup. Three roots (1 central incisor, 1 lateral incisor, 1 canine) from each of the subgroups $B$ and $C$ were not refilled and assigned as a control group $(n=12)$. Roots were stored at $37^{\circ} \mathrm{C}$ and $100 \%$ humidity for one week in airtight containers.

\section{Mechanical Testing}

All roots were dipped into molten wax and then embedded in acrylic resin (Metrodent Ltd, Huddersfield, UK). After the resin had set, it was immersed in hot water for 10 seconds to melt the wax and get the root out. The root surface and the resulting socket were cleaned from any remnants of wax and dried. Low-viscosity vinyl polysiloxane material (3M ESPE, St. Paul MN, USA) was then poured into the acrylic resin socket, and the root was repositioned into the socket resulting in a thin layer (0.22-0.32 $\mathrm{mm})$ of silicone to simulate the periodontal ligaments (Soares et al. 2005) (Figure 2). The blocks of resin with the fully embedded roots were mounted into a Universal Testing Machine (Zwick GmbH \& Co. KG, Germany). A tip with a round end (2.5 $\mathrm{mm}$ in diameter) was used to apply a vertical loading force directly above the root canal orifice. The force (Newtons [N]) was applied at a speed of $1 \mathrm{~mm} /$ minute until the root fractured. Fracture was 
considered as the point at which a sharp and instant drop of the applied force was observed. The test was terminated when a $25 \%$ drop in the maximum force recorded.

\section{Statistical Analysis}

SPSS Version 20.0 (IBM Corp., Armonk, US) was used at a level of significance of P $\leq$
0.05 . The test of normality (Shapiro-Wilk test) showed that data were not normally distributed and therefore, non-parametric tests were used. Data were analysed using the Kruskal-Wallis test with multiple pairwise comparisons.

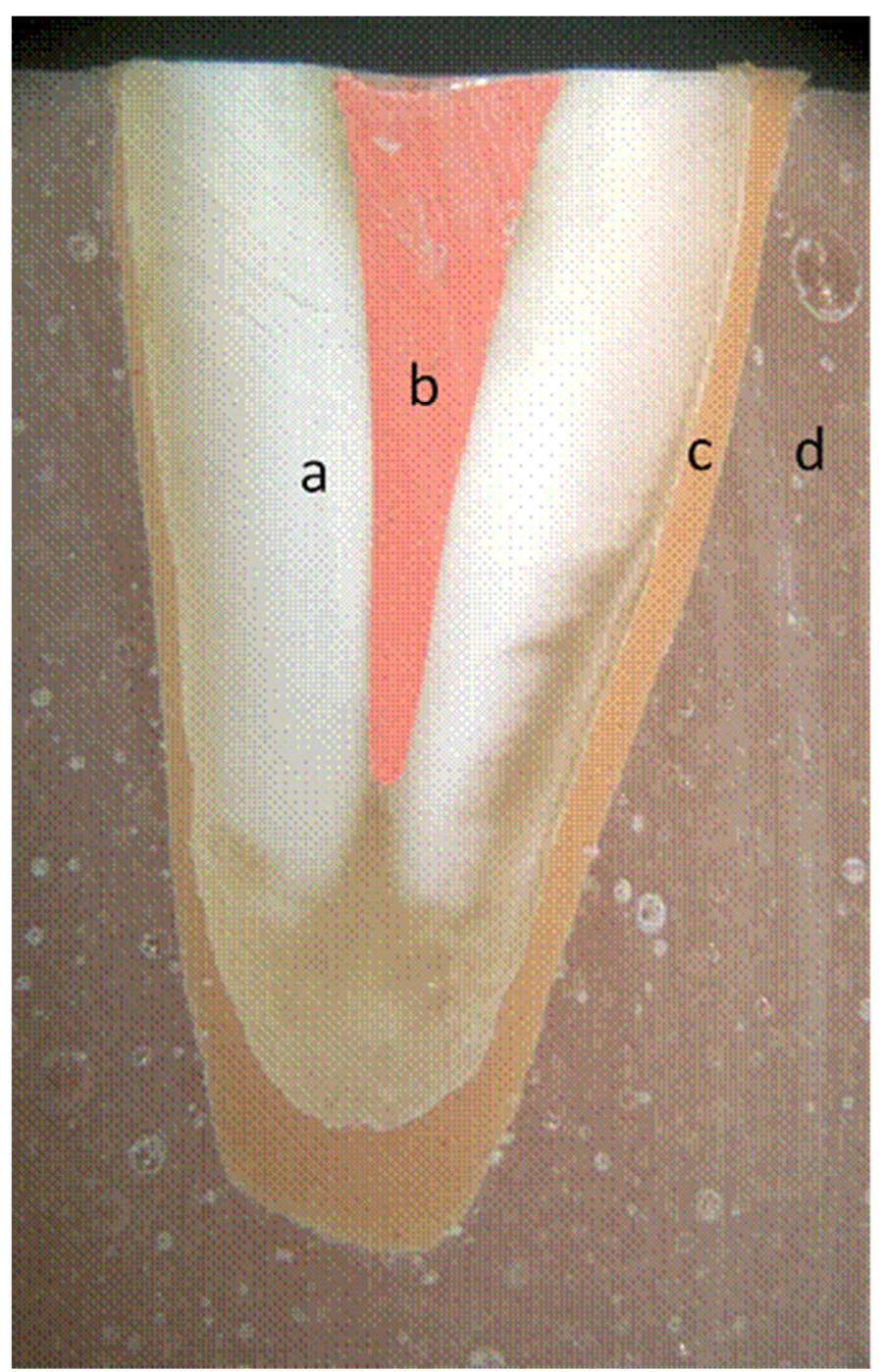

Figure 2: A Longitudinal Section of a Sample Illustrating Root (A) Filled with GuttaPercha (B), Surrounded by a Thin Layer of Silicone (C) and Embedded in Acrylic Resin (D) 


\section{Results}

Means and standard deviations of the force required to fracture for all groups are presented in Table 2 and Figure 3. There was no significant difference between the four non-refilled control subgroups which showed similar results when compared with all test subgroups, and therefore they were pooled into one representative control group. The results showed that the control group had significantly lower resistance to fracture than all filled groups regardless of the filling material or the retreatment technique. There was no significant difference in forces required to fracture between roots filled with Resilon and those filled with guttapercha, irrespective of the retreatment technique $(P>0.05)$. There was also no significant difference in the forces between the two retreatment techniques regardless of the obturation material $(P>0.05)$. Mode of fracture was bucco-lingually in $74 \%$ of the samples and oblique in 26\% (Figure 4).

Table 2: Means, Standard Deviations (SD) and Confidence Intervals (CI) of Force (Newtons) Required to Fracturing for All Subgroups

\begin{tabular}{|c|c|c|c|c|c|c|c|}
\hline \multirow{2}{*}{ Group } & \multirow{2}{*}{$\begin{array}{l}\text { Control } \\
\text { (non-refilled) }\end{array}$} & \multicolumn{3}{|c|}{ Guttapercha } & \multicolumn{3}{|l|}{ Resilon } \\
\hline & & ${ }^{*} \mathrm{~A}$ & $* * \mathrm{~B}$ & $* * * \mathrm{C}$ & A & $\mathrm{B}$ & $\mathrm{C}$ \\
\hline Mean & 169.36 & 261.06 & 281.44 & 245.42 & 366.38 & 339.52 & 289.89 \\
\hline SD & 10.01 & 63.78 & 67.12 & 24.39 & 72.75 & 61.63 & 57.19 \\
\hline
\end{tabular}

${ }^{*}$ A: No retreatment

${ }^{* *} \mathrm{~B}$ : Retreated with hand K-files and refilled with the same material in the first treatment

${ }^{* * *} \mathrm{C}$ : Retreated with ProTaper retreatment files and refilled with the same material in the first treatment

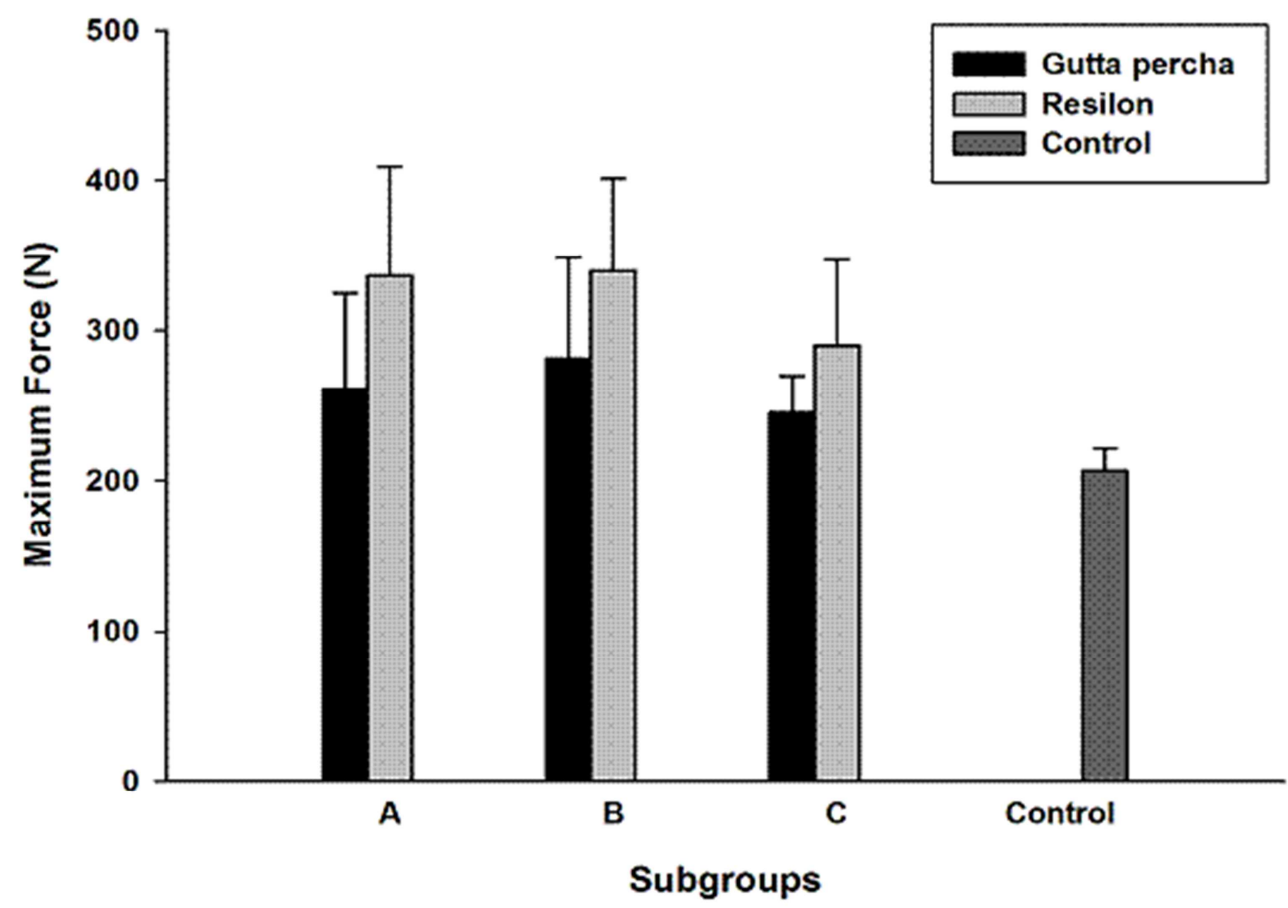

Figure 3: A Bar Chart Showing Means and Standard Deviations of Maximum Force (Newtons) at Fracture for Subgroups (A) No Retreatment (B) Retreated with Hand K-

Files and Refilled with the Same Material in the First Treatment (C) Retreated with Protaper Retreatment Files and Refilled with the Same Material in the First Treatment 


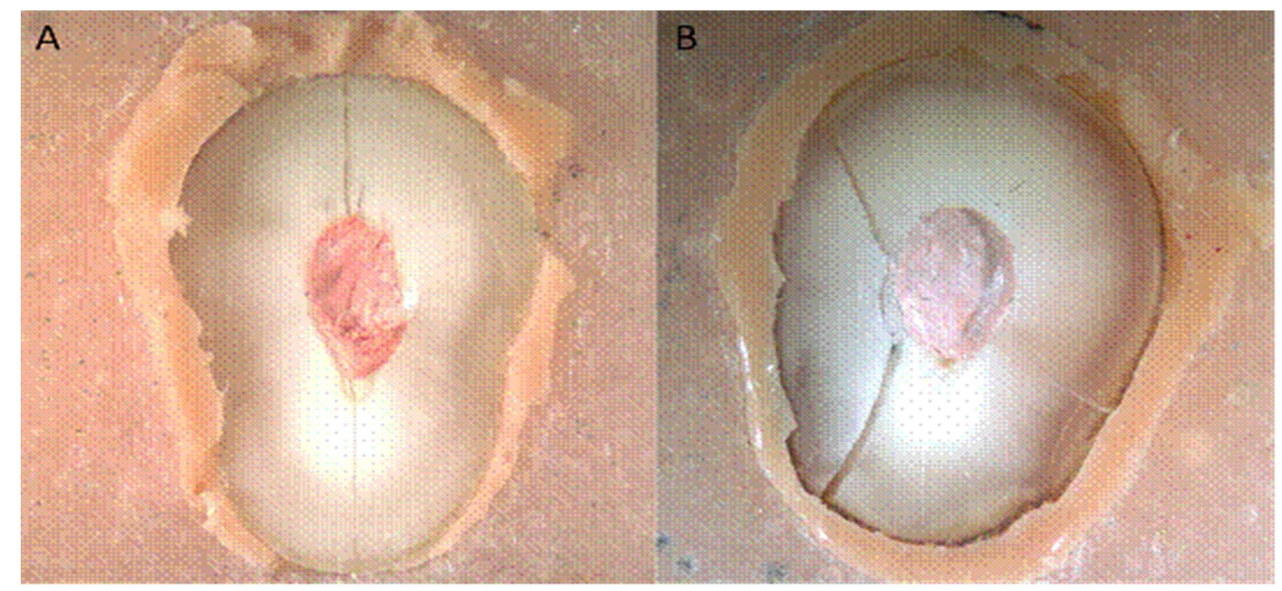

Figure 4: Mode of Fracture: (A) Bucco-Lingual, (B) Oblique

\section{Discussion}

This study showed that Resilon, as a root filling material, did not increase the fracture resistance of retreated and nonretreated roots in comparison with guttapercha. Properties of Resilon in retreatment, such as sealing ability and bond strength (Lin et al. 2007; Shokouhinejad et al. 2010), have been investigated. However, fracture resistance of roots refilled with Resilon has not been examined. Furthermore, the effect of either hand or rotary removal techniques on fracture resistance has not been investigated.

It has been claimed that Resilon has a root strengthening effect which has been attributed to its ability to form a monoblock with the dentine wall; whereby Resilon bonds to RealSeal sealer which in turn bonds to dentine (Tay and Pashley 2007). In the present study, Resilon did not improve the fracture resistance of primarily treated and retreated roots in comparison with guttapercha. This is in agreement with the findings of other reported works related to primary endodontic treatment (Ribeiro et al. 2008; Kazandag et al. 2009; Nagas et al. 2010; Sagsen et al. 2013) and contradicts others (Teixeira et al. 2004b; Hammad et al. 2007; Baba et al. 2010). Some other studies reported that the fracture resistance of Resilon-filled roots were significantly lower than guttapercha-filled roots (Ulusoy et al. 2007; Hanada et al. 2010). The contradiction may be due to differences in the samples preparation and study design. The roots in both studies (Ulusoy et al. 2007; Hanada et al. 2010) were embedded in resin without the use of silicone tubing.

In order to prevent debonding of a resin material as a result of stress concentration at the interface with dentine, the material should have a modulus of elasticity similar to that of dentine (Williams et al. 2006). The modulus of elasticity of dentine is about 16,000 MPa (Kinney et al. 1999), whereas that of Resilon is about $86.58 \mathrm{MPa}$ (Williams et al. 2006) which is far below the dentine. Therefore, the ability of Resilon to strengthen endodontically treated roots has been questioned (Williams et al. 2006; Grande et al. 2007).

The use of silicone tubing around the root to simulate the cushioning effect of the periodontal tissues was used because it has been shown that unusually high forces to fracture might be necessary otherwise (Trope and Ray 1992; Lertchirakarn et al. 2002; Kishen 2006). The light-body condensation reaction silicone was used in the present study because it has a modulus of elasticity of $0.26 \mathrm{MPa}$ (Jamani et al. 1989) which is approximate to that of the human periodontal ligaments (0.11-0.96 MPa) (Yoshida et al. 2001). Full coverage of roots with silicone and acrylic resin was adopted to simulate clinical situation. 1\% $\mathrm{NaOCl}$ was used as the irrigant in this experiment. It has been shown that high concentrations of $\mathrm{NaOCl}$ can significantly 
reduce the microhardness, flexural strength and modulus of elasticity of root canal dentine (Sim et al. 2001; SlutzkyGoldberg et al. 2004). As all root canals were irrigated with the same concentration of $\mathrm{NaOCl}$, all samples should be equally affected.

As this is an in vitro study, it does not take into consideration the in vivo tissue response. In addition, the natural variations in the anatomy of human teeth may influence the strength of the roots. However, the number of variables was decreased by standardising factors, such as root length and final size of canal preparation, and by equal allocation of upper anterior teeth in each group using stratified sampling and selecting comparable bucco-lingual and mesio-distal dimensions.

In conclusion, the current findings add to a growing body of literature which question the root strengthening effect of Resilon and indicate that it still could not be a replacement of guttapercha. Further, in vivo investigation is warranted.

\section{Acknowledgment}

The authors would like to thank Dr. Tanya Walsh for her helpful advice on the statistical analysis of the data.

\section{References}

Baba, S. M., Grover, S. I. \&Tyagi, V. (2010). "Fracture Resistance of Teeth Obturated with GuttaPercha and Resilon: An in Vitro Study," Journal of Conservative Dentistry, 13 (2) 61-64.

Goodacre, C. J. (2004). "Five Factors to be Considered when Restoring Endodontically Treated Teeth," Practical Procedures \& Aesthetic Dentistry, 16 (6) 457-462.

Grande, N. M., Plotino, G., Lavorgna, L., Ioppolo, P., Bedini, R., Pameijer, C. H. \&Somma, F. (2007). "Influence of Different Root Canal-Filling Materials on the Mechanical Properties of Root Canal Dentin," Journal of Endodontics, 33 (7) 859863.
Hammad, M., Qualtrough, A. \&Silikas, N. (2007). "Effect of New Obturating Materials on Vertical Root Fracture Resistance of Endodontically Treated Teeth," Journal of Endodontics, 33 (6) 732-736.

Hammad, M., Qualtrough, A. \&Silikas, N. (2008). "Three-Dimensional Evaluation of Effectiveness of Hand and Rotary Instrumentation for Retreatment of Canals Filled with Different Materials," Journal of Endodontics, 34 (11) 1370-1373.

Hanada, T., Quevedo, C. G. A., Okitsu, M., Yoshioka, T., Iwasaki, N., Takahashi, H. \&Suda, H. (2010). "Effects of New Adhesive Resin Root Canal Filling Materials on Vertical Root Fractures," Australian Endodontic Journal, 36 (1) 19-23.

Jamani, K. D., Harrington, E. \& Wilson, H. J. (1989). "Rigidity of Elastomeric Impression Materials," Journal of Oral Rehabilitation, 16 (3) 241-248.

Kazandag, M. K., Sunay, H., Tanalp, J. \&Bayirli, G. (2009)."Fracture Resistance of Roots Using Different Canal Filling Systems," International Endodontic Journal, 42 (8) 705-710.

Kinney, J. H., Balooch, M., Marshall, G. W. \& Marshall, S. J. (1999). "A Micromechanics Model of the Elastic Properties of Human Dentine," Archives of Oral Biology, 44 (10) 813-822.

Kishen, A. (2006). "Mechanisms and Risk Factors for Fracture Predilection in Endodontically Treated Teeth," Endodontic Topics, 13 (1) 57-83.

Lertchirakarn, V., Timyam, A. \& Messer, H. H. (2002). "Effects of Root Canal Sealers on Vertical Root Fracture Resistance of Endodontically Treated Teeth," Journal of Endodontics, 28 (3) 217-219.

Lin, Z. M., Jhugroo, A. \& Ling, J. Q. (2007)."An Evaluation of the Sealing Ability of a Polycaprolactone-Based Root Canal Filling Material (Resilon) after Retreatment," Oral Surgery, Oral Medicine, Oral Pathology, Oral Radiology, and Endodontology, 104 (6) 846-851. 
Miner, M. R., Berzins, D. W. \&Bahcall, J. K. (2006). "A Comparison of Thermal Properties between Gutta-Percha and a Synthetic Polymer Based Root Canal Filling Material (Resilon)," Journal of Endodontics, 32 (7) 683-686.

Monteiro, J., de Ataide, I. N., Chalakkal, P. \& Chandra, P. K. (2011). "In Vitro Resistance to Fracture of Roots Obturated with Resilon or Gutta-Percha," Journal of Endodontics, 37 (6) 828-831.

Nagas, E., Uyanik, O., Altundasar, E., Durmaz, V., Cehreli, Z. C., Vallittu, P. K. \&Lassila, L. V. J. (2010). "Effect of Different Intraorifice Barriers on the Fracture Resistance of Roots Obturated with Resilon or Gutta-Percha," Journal of Endodontics, 36 (6) 1061-1063.

Ribeiro, F. C., Souza-Gabriel, A. E., Marchesan, M. A., Alfredo, E., Silva-Sousa, Y. T. C. \& Sousa-Neto, M. D. (2008). "Influence of Different Endodontic Filling Materials on Root Fracture Susceptibility," Journal of Dentistry, 36 (1) 69-73.

Sagsen, B., Zortuk, M., Ertas, H., Er, O., Demirbuga, S. \&Arslan, H. (2013)."In Vitro Fracture Resistance of Endodontically Treated Roots Filled with a Bonded Filling Material or Different Types of Posts," Journal of Endodontics, 39 (11) 1435-1437.

Schneider, S. W. (1971). "A Comparison of Canal Preparations in Straight and Curved Root Canals," Oral Surgery, Oral Medicine, Oral Pathology, 32 (2) 271-275.

Schwartz, R. S. (2006). "Adhesive Dentistry and Endodontics. Part 2: Bonding in the Root Canal System - The Promise and the Problems: A Review," Journal of Endodontics, 32 (12) 1125-1134.

Shipper, G., Ørstavik, D., Teixeira, F. B. \& Trope, M. (2004). "An Evaluation of Microbial Leakage in Roots Filled with a Thermoplastic Synthetic Polymer-Based Root Canal Filling Material (Resilon)," Journal of Endodontics, 30 (5) 342-347.
Shokouhinejad, N., Sabeti, M. A., Hasheminasab, M., Shafiei, F. \&Shamshiri, A. R. (2010). "Push-Out Bond Strength of Resilon/Epiphany Self-Etch to Intraradicular Dentin after Retreatment: A Preliminary Study," Journal of Endodontics, 36 (3) 493-496.

Sim, T. P. C., Knowles, J. C., Ng, Y.- L., Shelton, J. \&Gulabivala, K. (2001). "Effect of Sodium Hypochlorite on Mechanical Properties of Dentine and Tooth Surface Strain," International Endodontic Journal, 34 (2) 120-132.

Slutzky-Goldberg, I., Maree, M., Liberman, R. \&Heling, I. (2004). "Effect of Sodium Hypochlorite on Dentin Microhardness," Journal of Endodontics, 30 (12) 880-882.

Soares, C. J., Pizi, E. C., Fonseca, R. B. \& Martins, L. R. (2005). "Influence of Root Embedment Material and Periodontal Ligament Simulation on Fracture Resistance Tests," Brazilian Oral Research, 19 (1) 11-16.

Sornkul, E. \&Stannard, J. G. (1992). "Strength of Roots before and after Endodontic Treatment and Restoration," Journal of Endodontics, 18 (9) 440-443.

Tamse, A. (2006). "Vertical Root Fractures in Endodontically Treated Teeth: Diagnostic Signs and Clinical Management," Endodontic Topics, 13 (1) 84-94.

Tay, F. R. \&Pashley, D. H. (2007). "Monoblocks in Root Canals: A Hypothetical or a Tangible Goal," Journal of Endodontics, 33 (4) 391-398.

Teixeira, F. B., Teixeira, E. C. N., Thompson, J. Y., Leinfelder, K. F. \& Trope, M. (2004a). "Dentinal Bonding Reaches the Root Canal System," Journal of Esthetic and Restorative Dentistry, 16 (6) 348-354. 
Teixeira, F. B., Teixeira, E. C. N., Thompson, J. Y. \& Trope, M. (2004b). "Fracture Resistance of Roots Endodontically Treated with a New Resin Filling Material," The Journal of the American Dental Association, 135 (5) 646-652.

Teixeira, F. B. \& Trope, M. (2004). "GuttaPercha--The End of An Era?," Alpha Omegan, 97 (4) 16-22.

Trope, M. \& Ray, H. L. (1992). "Resistance to Fracture of Endodontically Treated Roots," Oral Surgery, Oral Medicine, Oral Pathology, 73 (1) 99-102.

Ulusoy, Ö. İ. A., Genç, Ö.,Arslan, S., Alaçam, T. \&Görgül, G. (2007). "Fracture Resistance of Roots Obturated with Three Different Materials," Oral Surgery, Oral Medicine, Oral Pathology, Oral Radiology, and Endodontology, 104 (5) 705-708.
Wilcox, L. R., Roskelley, C. \& Sutton, T. (1997). "The Relationship of Root Canal Enlargement to Finger-Spreader Induced Vertical Root Fracture," Journal of Endodontics, 23 (8) 533-534.

Williams, C., Loushine, R. J., Weller, R. N., Pashley, D. H. \&Tay, F. R. (2006). "A Comparison of Cohesive Strength and Stiffness of Resilon and Gutta-Percha," Journal of Endodontics, 32 (6) 553-555.

Yoshida, N., Koga, Y., Peng, C.- L., Tanaka, E. \& Kobayashi, K. (2001). "In Vivo Measurement of the Elastic Modulus of the Human Periodontal Ligament," Medical Engineering \& Physics, 23 (8) 567-572. 